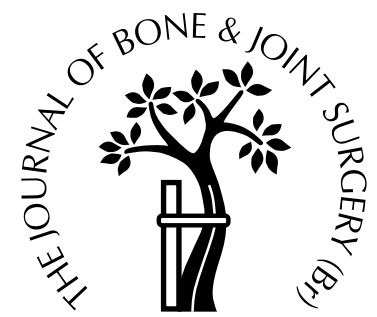

\title{
Damage to the superior gluteal nerve after two different approaches to the hip
}

\author{
P. Kenny, C. P. O’Brien, K. Synnott, M. G. Walsh \\ From Cappagh Orthopaedic Hospital, Finglas, Dublin, Ireland
}

W e have carried out a blind, prospective study of 50 consecutive patients undergoing replacement arthroplasty of the hip using two different approaches. Clinical assessment, including the Harris hip score and a modified Trendelenberg test, and electrophysiological examination of the abductor muscles of the hip were undertaken before and three months after surgery. We found that $48 \%$ of patients had preoperative evidence of chronic injury to the superior gluteal nerve. Perioperative injury to the nerve occurred commonly with both approaches to the hip.

We did not find a significant correlation between injury to the superior gluteal nerve and clinical problems.

J Bone Joint Surg [Br] 1999;81-B:979-81.

Received 24 September 1998; Accepted after revision 15 March 1999

The superior gluteal nerve may be compromised during total hip arthroplasty. ${ }^{1}$ The direct lateral approach of Hardinge puts this nerve at risk when the gluteus medius is split and retracted anteriorly. ${ }^{2}$ We have made a prospective study of 50 consecutive patients undergoing total hip arthroplasty, to establish whether there was a greater incidence of injury to the superior gluteal nerve associated with a particular approach to the hip. The operating surgeons used either a direct lateral or a transtrochanteric approach, in accordance with their normal practice. The patients were assessed clinically and electrophysiologically before and at three months after operation.

\section{Patients and Methods}

All 50 patients suffered from primary osteoarthritis and all gave informed consent. Patients were excluded from the

P. Kenny, FRCS I, Orthopaedic Registrar

C. P. O'Brien, PhD, Neurophysiologist

K. Synnott, FRCS I, Orthopaedic Registrar

M. G. Walsh, FRCS I, Consultant Orthopaedic Surgeon

Cappagh Orthopaedic Hospital, Finglas, Dublin 11, Ireland.

Correspondence should be sent to Mr P. Kenny at 107 Booterstown Avenue, Blackrock, Co. Dublin, Ireland.

(C)1999 British Editorial Society of Bone and Joint Surgery 0301-620X/99/69509\$2.00

VOL. 81-B, No. 6, NOVEMBER 1999 study if there was a known history or any signs of abnormal nerve function. Two patients were withdrawn from the study after the initial assessment. The remaining 19 men and 29 women had a mean age of 69.8 years (52 to 83). The direct lateral approach, as described by Hardinge, was used in 25 and the transtrochanteric approach in 23. The mean operating time was 90.3 minutes for the direct lateral group and 94 minutes for the transtrochanteric group. In each case preoperative needle electromyographiy (EMG) was carried out to examine the superior gluteal nerve supplying the gluteus medius, gluteus minimus and tensor fascia lata. The more distal muscles, vastus medialis (L4), tibialis anterior (L5) and medial gastrocnemius (SI), were also assessed to determine if there was any evidence of a more widespread denervating process, such as lumbar radiculopathy, which would compromise the roots of the superior gluteal nerve (L4, L5, S1).

The EMGs were carried out by a clinical neurophysiologist (CO'B). The muscles were examined using the criteria of the American Academy of Electrophysiological Medicine for needle EMG. ${ }^{3}$ Rest and insertional activity was assessed first, followed by observations of the recruitment pattern and the motor unit action potential (MUAP).

Acute or ongoing denervation was diagnosed if there was increased insertional activity $(>300 \mathrm{~m} / \mathrm{s})$, evidence of positive sharp waves, fibrillation potentials, complex repetitive discharges or other abnormal rest or insertional potentials. ${ }^{4}$ Ongoing denervation or re-innervation was determined by the morphology and amplitude, duration and firing pattern of the MUAP.

A further needle EMG of the muscles innervated by the superior gluteal nerve was undertaken three months after operation (mean 99 days; range 55 to 130). The physician was not aware of which approach had been used or of the signs at clinical examination.

Acute denervation potentials are not observed for at least three weeks after a nerve injury. An abnormal postoperative EMG in our study was recorded only if there had been a change in insertional activity or recruitment pattern of the MUAP or morphology from the preoperative examination.

We used the Harris hip score to assess patients before and after operation, and each was examined for the presence of the Trendelenberg sign. 
buttock through the greater sciatic foramen, above the

Two patients were withdrawn from the study after the initial electrophysiological assessment. One had findings consistent with a demyelinating disorder and was referred to a neurologist for further investigation. The second patient was a schizophrenic and abnormalities on her initial assessment were attributed to her medication. A further six patients declined follow-up examination.

Electrophysiological studies before operation. The preoperative EMG was normal in 25 of the 48 patients (52\%). Of the remaining 23 (48\%), 22 showed evidence of chronic denervation or re-innervation and one of acute-on-chronic denervation of the hip abductors; 17 of these patients (74\%) had abnormalities in the L4, L5 and S1 myotomes, one in the S1 myotome, one in L4, and one in L5. The remaining three patients had two myotomes affected.

Clinical assessment before operation. The Trendelenberg sign was positive before operation in 35 patients (73\%). Of these, 19 (54\%) also had an abnormal EMG. Of the 13 patients $(27 \%)$ who had a negative Trendelenberg sign preoperatively, five (38\%) had an abnormal preoperative EMG.

The mean preoperative Harris hip score for the 48 patients was 46 (10 to 68 ). There was no correlation between the Harris hip score and EMG abnormalities.

At approximately three months after operation, 42 patients were reviewed; 19 had the procedure through a transtrochanteric approach and 23 by a direct lateral approach.

Electrophysiological studies after operation. In all, 22 patients (52\%) had an abnormal EMG with evidence of a recent injury to the superior gluteal nerve three months after operation. In two of these (9\%), two of the three muscles were affected, in three (14\%) only one and in the remaining $17(77 \%)$ all three muscles showed abnormality.

In the transtrochanteric group nine of 19 patients (47\%), and in the Hardinge group 13 of 23 (56\%), had an abnormal postoperative EMG (Table I).

These data were analysed using the chi-squared test giving a value of 55\%. Using Yates' correction, the chisquared value was $77 \%$. These figures confirm that there is no significant difference in the incidence of damage to the superior gluteal nerve, as demonstrated electrophysiologically, whether the approach is transtrochanteric or direct lateral.

Clinical assessment after operation. After operation, 11 of 42 patients $(26 \%)$ had a positive Trendelenberg sign (Table II), seven from the Hardinge group and four from the transtrochanteric group. The Trendelenberg sign was negative in 31 patients (74\%) (Table II). The mean postoperative Harris hip score was 85 (58 to 100). There was no correlation between this score and the EMG findings.

\section{$\underline{\text { Discussion }}$}

The roots of the superior gluteal nerve (L4, L5, S1) arise within the pelvis from the sacral plexus, and enter the piriformis. The nerve runs laterally between gluteus medius and gluteus minimus. It is in this region that it is at risk during surgery on the hip. It supplies both gluteus medius and gluteus minimus before terminating in the tensor fascia lata.

The relationship between nerve palsy and the surgical approach used for total hip arthroplasty has been assessed by several authors. Schmalzried, Amstutz and Dorey ${ }^{5}$ reviewed over 3000 hip replacements and identified postoperative neuropathy in 39 patients $(1.3 \%)$. The sciatic nerve was involved in 34 . Navarro et $\mathrm{al}^{6}$ found an overall prevalence of nerve palsy of $0.6 \%$ after a posterior approach and $1 \%$ after a lateral approach. Oldenburg and Muller ${ }^{7}$ reported an incidence of postoperative neuropathy of $2.24 \%$. The nerves injured were the sciatic, the peroneal and the femoral. Other large studies and review articles have reported nerve injuries after total hip arthroplasty. ${ }^{8,9}$ Weale et al, ${ }^{10}$ using EMG and nerve-conduction velocity, found that clinical assessment alone underestimated the incidence of nerve injury. In none of the studies quoted above is injury to the superior gluteal nerve specifically recorded. This may be because it has no sensory distribution and therefore patients do not complain, or that weakness of the abductor muscle is attributed to mechanical rather than to neurological dysfunction.

Abitbol et $\mathrm{al}^{1}$ investigated the incidence of injury to the superior and inferior gluteal nerves using EMG. Subclinical gluteal nerve injury was detected in $77 \%$ of patients, irrespective of whether a posterior or a lateral approach to the hip was used. Ramesh et al $^{2}$ assessed 81 patients who had undergone a direct lateral (Hardinge) approach to the hip. They found that $11 \%$ of patients showed complete denervation of the superior gluteal nerve on EMG, three months after surgery. Persistent damage to the nerve was associated with a positive Trendelenberg test.

We obtained an EMG before operation in order to evaluate the true incidence of intraoperative injury. Since most patients requiring total hip arthroplasty are elderly and, in our group, had primary osteoarthritis, it is to be expected that there is an incidence of degenerative disease of the

Table I. The results of postoperative EMGs in 42 patients showing the number $(\%)$ of patients with perioperative nerve injury and the approach to the hip used

\begin{tabular}{llll}
\hline Approach to the hip & No change & $\begin{array}{l}\text { Perioperative } \\
\text { nerve injury }\end{array}$ & Total \\
\hline Transtrochanteric & $10(53)$ & $9(47)$ & $19(100)$ \\
Direct lateral & $10(45)$ & $13(56)$ & $23(100)$ \\
Total & $20(48)$ & $22(52)$ & $42(100)$ \\
\hline
\end{tabular}

Table II. The postoperative Trendelenberg signs for the 42 patients and the numbers $(\%)$ of patients with or without acute nerve injury

\begin{tabular}{lcc}
\hline & EMG & \\
\cline { 2 - 3 } Trendelenberg sign & Acute nerve injury & No nerve injury \\
\hline Positive & $8(73)$ & $3(27)$ \\
Negative & $14(45)$ & $17(55)$ \\
\hline
\end{tabular}

THE JOURNAL OF BONE AND JOINT SURGERY 
lumbar spine which could cause chronic lumbar radiculopathy. Denervation of the muscles innervated by the superior gluteal nerve as a result of abnormality of a lumbar or sacral root is clearly possible. Therefore we also examined the vastus medialis, tibialis anterior and the medial head of gastrocnemius which have maximum innervation from L4, L5 and S1. $A$ change between preoperative and postoperative EMG was taken to signify an acute injury to the nerve.

The clinical findings and EMG studies did not correlate which suggests that factors other than injury to the superior gluteal nerve may be responsible for a positive Trendelenberg sign. Nutton and Checketts ${ }^{12}$ showed that nonunion after trochanteric osteotomy may result in impairment of gait but Frankel et $\mathrm{al}^{13}$ found this in only $17 \%$ of patients with this complication. In our series, one patient had evidence of trochanteric nonunion when seen at three months after operation. She had a positive Trendelenberg sign and a normal postoperative EMG. Baker and Bitounis ${ }^{14}$ considered that weakness of the abductor muscles after a direct lateral approach to the hip is usually a result of detachment of the gluteal flap. They also suggested that a traction injury to the superior gluteal nerve results in denervation of the tensor fascia lata and therefore to abductor weakness.

The results of our study have shown evidence of chronic nerve injury before operation, as determined by EMG, in $48 \%$ of patients undergoing total hip arthroplasty for primary osteoarthritis. We have shown that injury to the superior gluteal nerve is a common complication of the procedure irrespective of whether a transtrochanteric or a direct lateral approach is used. The cause of a Trendelenberg gait after total hip replacement is multifactorial. EMG evidence of an acute nerve injury does not correlate with clinical findings of weak abduction or with the Harris hip score. Injury to the superior gluteal nerve may be a contributary factor to a positive Trendelenberg test, but other influences must also be present.

No benefits in any form have been received or will be received from a commercial party related directly or indirectly to the subject of this article.

\section{References}

1. Abitbol JJ, Gendron D, Laurin CA, Beaulieu MA. Gluteal nerve damage following total hip arthroplasty: a prospective analysis. $J$ Arthroplasty 1990;5:319-22.

2. Ramesh M, O'Byrne JM, McCarthy N, et al. Damage to the superior gluteal nerve after the Hardinge approach to the hip. $J$ Bone Joint Surg [Br] 1996;78-B:903-6.

3. Daube JR. AAEM Minimonograph. No. 11: needle examination in clinical electromyography. Muscle nerve 1991;8:685-700.

4. Berry M. Traumatic peripheral nerve lesions. In: Brown WF, Bolton C, eds. Clinical electromyography. Boston, etc: Butterworth-Heinmann 2nd Ed, 1993:323-68.

5. Schmalzried TP, Amstutz HC, Dorey FJ. Nerve palsy associated with total hip replacement: risk factors and prognosis. J Bone Joint Surg [Am] 1991;73-A:1074-80.

6. Navarro RA, Schmalzried TP, Amstutz HC, Dorey FJ. Surgical approach and nerve palsy in total hip arthroplasty. J Arthroplasty 1995;10:1-5.

7. Oldenburg M, Muller RT. The frequency, prognosis and significance of nerve injuries in total hip arthroplasty. Int Orthop 1997;21:1-3.

8. Nercessian OA, Macaulay W, Stinchfield FE. Peripheral neuropathies following total hip arthroplasty. J Arthroplasty 1994;9: 645-51.

9. Simmons C, Izant TH, Rothmans RH, Booth RE, Balderston RA. Femoral neuropathy following total hip arthroplasty: anatomic study, case reports and literature review. J Arthroplasty 1991;6:557-66.

10. Weale AE, Newman P, Ferguson IT, Bannister GC. Nerve injury after posterior and direct lateral approaches for hip replacement: a clinical and electrophysiological study. J Bone Joint Surg [Br] 1996; 78-B:899-902.

11. Wilborne AJ, Amnoff MI. Radiculopathies. In: Brown WF, Bolton C, eds. Clinical electromyography. Boston, etc: Butterworth-Heinmann 2nd edition, 1993:175-210.

12. Nutton RW, Checketts RG. The effects of trochanteric osteotomy on abductor power. J Bone Joint Surg [Br] 1984;66-B:180-3.

13. Frankel A, Booth RE, Balderston RA, Cohn J, Rothman RH. Complications of trochanteric osteotomy: long term implications. Clin Orthop 1993;288:209-13.

14. Baker AS, Bitounis VC. Abductor function after total hip replacement: an electromyographic and clinical review. J Bone Joint Surg [Br] 1989;71-B:47-50. 